Rev.MVZ Córdoba 13(3):1456-1463, 2008

ORI GI NAL

\title{
EVALUACIÓN DE LAS PROPIEDADES DEL CAJARO (Phractocephalus hemiliopterus) COMO POTENCIAL PARA LA OBTENCIÓN DE SURIMI Y PRODUCTOS DERI VADOS
}

\author{
EVALUATI ON OF THE PROPERTIES OF THE RED-TAILED \\ CATFISH (Phractocephalus hemiliopterus) AS A POTENTI AL \\ SPECIES FOR OBTAI NI NG SURI MI AND DERI VED PRODUCTS
}

\author{
Indira Sotelo D,* Ph.D, Annamaria Filomena A, Ing, Jenny Rodríguez P, Ing. \\ Universidad de La Sabana. Campus Universitario del Puente del Común Km. 21 Autopista \\ Norte de Bogotá, D.C. Chía, Colombia.*Corespondencia: indira.sotelo@unisabana.edu.co
}

Recibido: Junio 18 de 2008; Aceptado: Diciembre 5 de 2008

\section{RESUMEN}

Objetivo. Determinar el uso potencial de carne de Cajaro (Phractocephalus hemiliopterus), para la obtención de surimi y productos derivados. Materiales y métodos. Filetes de Cajaro fueron troceados y lixiviados con agua en relación 1:3, formando pasta base surimi con la cual se preparó kamaboko, sometiendo la pasta moldeada a vapor $\left(60^{\circ} \mathrm{C}\right)$ durante $15 \mathrm{~min}$; y chikuwa donde la pasta en forma de rollo fue cocida a $80^{\circ} \mathrm{C}$ por 10 min. Se determinó la proteína total por método Kjeldahl, la capacidad de retención de agua (CRA) y el análisis de perfil de textura (TPA). El contenido de humedad se determinó por método AOAC (985.14) y se evaluó la calidad de la proteína miofibrilar por electroforesis SDS-page. Resultados. El Cajaro presentó un contenido proteico de $17.90 \pm 0.79 \%$ b.h.; porcentaje de humedad de $81.65 \pm 2.2 \%$ b.h. y CRA de $66.25 \pm 3.53 \%$ b.h. Los productos derivados presentaron $18.66 \pm 1.35 \%$ b.h., de proteína total equivalente a la proteína miofibrilar, influyendo en la gelificación por aumento de la CRA con respecto al surimi. El TPA incrementó (á=0.05) en la masticabilidad de la pasta base ( 51.04 N.s) con respecto al kamaboko (480.80 N.s), generando características cohesivas a los productos derivados, frente a características adhesivas de la pasta base. En la electroforesis se evidenció que la calidad de la miosina en productos derivados se conservó después de congelados, mientras que en filete y pasta base se deterioró. Conclusiones. La calidad de la proteína miofibrilar de Cajaro evidencia el potencial tecnológico que tiene esta especie del Amazonas, convirtiéndose en una oportunidad de negocio para obtención de productos tipo surimi de alto valor nutricional con calidad exportable.

Palabras clave: Phractocephalus hemiliopterus, surimi, proteína miofibrilar. 


\section{ABSTRACT}

Objective. To assess the potential use of red-tailed catfish (Phractocephalus hemiliopterus) meat for the production of surimi and derived products. Materials and methods. Red-tailed catfish fillets where minced and combined with water ( 1 part fish to 3 parts water) to form surimi paste. Kamaboko was prepared by steaming the molded paste $\left(60^{\circ} \mathrm{C}\right)$ for 15 minutes; Chikuwa was prepared by rolling the Surimi and baking $\left(80^{\circ} \mathrm{C}\right)$ for $10 \mathrm{~min}$. Total protein was determined by the Kjeldahl method, WHC and TPA. Moisture content was determined by the AOAC (985.14) method and myofibrilar protein quality was evaluated by SDS-page electrophoresis. Results. Protein content of red-tailed catfish meat was $17.90 \pm 0.79 \%$ h.b., water content $81.65 \pm 2.2 \%$ h.b and CRA $66.25 \pm 3.53 \%$ h.b. Compared to surimi, the derived products had $18.66 \pm 1.35 \%$ h.b., of total protein equivalent to myofibrilar protein, which influences gelling due to the increase in WHC. TPA increased (á=0.05) the chewabililty of the paste ( $51.04 \mathrm{~N} . \mathrm{s})$ compared to kamaboko (480.80 N.s); giving cohesive attributes to the derived products compared the adhesive properties of the surimi paste. The SDS-page electrophoresis showed that the myosin quality in the derived products was retained after freezing, while in fillets and in surimi it deteriorated. Conclusions. The quality of the myofibrilar protein of red-tailed catfish meat suggests technological potential of this Amazonian species that may represent a business opportunity for the production of surimi products of high nutritional value and exportable quality.

Key words: Phractocephalus hemiliopterus, surimi, myofibrilar protein.

\section{NTRODUCCI ÓN}

Colombia se ha ubicado como el tercer país del mundo en recursos hídricos en proporción a su extensión y cuenta ademas, con gran diversidad de especies pesqueras, lo que hace evidente el compromiso de dar valor agregado a especies nativas provenientes de las cuencas colombianas en forma sostenible, puesto que representan 40.000 toneladas anuales de la producción total que aporta $0.51 \%$ al PIB del país (1). Existe un mercado potencial para productos pesqueros, pues el consumo mundial (excluyendo China) se ha incrementado $2.5 \%$ anual desde 1961 (2), por lo tanto, hay oportunidad de desarrollar procesos de conservación y adecuación de pescado con estándares internacionales de calidad. Un buen ejemplo de alternativas de procesamiento que conserva las propiedades funcionales y nutricionales del pescado es la elaboración de surimi.

El término japonés surimi, se define como una pasta de proteínas miofibrilares concentradas, obtenidas al moler o trocear músculo del pescado que se somete a lixiviación con agua a baja temperatura
$(3,4)$, y es empleado en la manufactura e imitación de productos de mar. Para su elaboración se emplean especies marinas principalmente Abadejo de Alaska. En los últimos años el consumo de los productos a base de surimi se ha incrementado en el mundo, sin embargo, un gran descenso en su producción debida a la escasez y alto costo de las especies marinas empleadas para producirlo, ha motivado la utilización de otros recursos pesqueros, entre ellos las especies tropicales y de agua dulce (4). En la actualidad EEUU es uno de los mayores productores con 69.000 toneladas en el 2007, de las cuales 14.000 fueron exportadas principalmente hacia Japón, España y Francia (5).

Las proteínas miofibrilares del músculo de pescado poseen por sí mismas alta capacidad de gelificación, propiedad natural que puede afectarse durante el almacenamiento en refrigeración o congelación (6). El perfil proteico necesario para obtener las características texturales y la capacidad de retención de agua (CRA) típicas de surimi y productos derivados depende de la calidad 
y cantidad de las proteínas miofibrilares. Aproximadamente $70 \%$ del agua, se encuentra retenida dentro o entre las miofibrillas; las proteínas miofibrilares son responsables de la retención del agua en el músculo (7). Factores internos o externos como la modificación del pH o los procesos de homogenización respectivamente, producen un cambio en la CRA (8). Esta propiedad afecta la calidad de los productos cárnicos, influye en la vida útil del producto y afecta la economía de las industrias, debido a que la pérdida de agua se traduce en pérdida de dinero (9).

En búsqueda de nuevas especies para la producción de surimi y proporcionar valor agregado a especies de extracción, se evaluó el pescado Cajaro (Phractocephalus hemiliopterus), especie pimelodo (Siluriformes) perteneciente a los grandes bagres de la amazonía colombiana, que es una de las diez principales que sustentan la pesquería de la región y es comercializada en la ciudad de Bogotá.

\section{MATERI ALES Y MÉTODOS}

Materia prima. Se adquirió filete de Cajaro (Phractocephalus hemiliopterus) (Figura 1), en un distribuidor de pescado autorizado de la ciudad de Bogotá y fue conservado por 24 horas en congelación $\left(-18^{\circ} \mathrm{C}\right)$ hasta el procesamiento.

Elaboración de Surimi. Los filetes de pescado se limpiaron separando la fibra muscular (miotoma) de piel, hueso y cartílago; luego se sometieron a lixiviación con agua potable a $4^{\circ} \mathrm{C}$ en una relación $\mathrm{p} / \mathrm{p}$ 1:3 (filete: agua), durante períodos de 15 a 20 min., en tres etapas sucesivas, para retirar la mayor proporción posible de proteínas sarcoplásmicas, que impiden la formación de la estructura del gel. Se realizó prensado manual con un lienzo para retirar el exceso de agua y proteína sarcoplásmica. Posteriormente se homogenizó con $\mathrm{NaCl}$ $(0.1 \% \mathrm{p} / \mathrm{p})$, sacarosa $(0.5 \% \mathrm{p} / \mathrm{p})$ y polifosfatos $(0.2 \% \mathrm{p} / \mathrm{p})$. La pasta obtenida (Surimi) fue empacada en bolsas cryovac ${ }^{\circledR}$ de poliestireno de alta densidad en condiciones de vacío (empacadora Oster, FoodSaver ${ }^{\mathrm{TM}}$ ) y almacenada en congelación

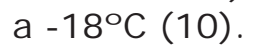

\section{Elaboración de productos derivados}

Kamaboko. La pasta base se moldeó en forma de hamburguesa y se sometió a tratamiento térmico con vapor directo a $60 \circ \mathrm{C}$ durante $15 \mathrm{~min}$., hasta obtener un gel coagulado.

Chikuwa. La pasta base se dispuso en forma de hoja rectangular para ser enrollada en una barra de metal y se sometió a cocción en horno a $80^{\circ} \mathrm{C}$ durante 10 min., hasta gelificación de la misma.

Diseño del estudio. Se siguió un diseño experimental completamente aleatorio, con tres ensayos independientes, conformado por cuatro tratamientos (carne de cajaro fresco, surimi, kamaboko y chikuwa); se evaluó la respuesta a cinco factores: Humedad, CRA, textura, nitrógeno total y proteína miofibrilar. Todas las determinaciones analíticas fueron realizadas por triplicado.
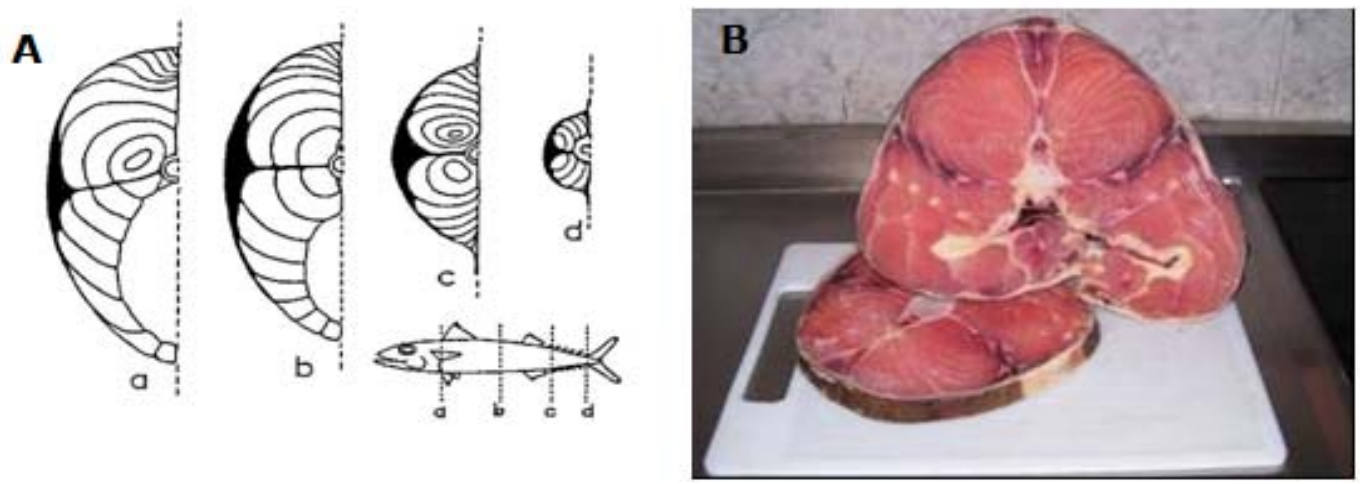

Figura 1. A. Disposición del miotoma, B. Filetes de Cajaro fresco. 
Determinación de humedad. Se empleó el método de secado en estufa AOAC (985.14) (11).

Capacidad de retención de agua (CRA). Muestras de $1,500 \pm 0.100 \mathrm{~g}$ fueron cubiertas en papel de filtro Whatman \#3 previamente pesado y este a su vez fue cubierto por papel de filtro \#50. Se centrifugaron a $9.500 \mathrm{~g}$ durante $20 \mathrm{~min}$ a $4 \stackrel{\circ}{ } \mathrm{C}$. El agua retenida se pesó en el papel de filtro \#3 (12).

Analisis de perfil de textura (TPA). Se determinó la fuerza de corte, cohesividad y adhesividad, con un texturómetro TA-XT2 de Stable Microsystems; se utilizó una sonda $\mathrm{P} / 25$ cilindro de aluminio diámetro $25 \mathrm{~mm}$., con una velocidad de ensayo de $2.0 \mathrm{~mm} / \mathrm{s}$ a una distancia de $8 \mathrm{~mm}$.

Determinación de proteínas. Se empleó el método de cuantificación de nitrógeno total, Kjeldahl, AOAC, 984.13 (11), en equipo Kjeldahl Line marca Buchi.

Extracción de proteína miofibrilar. Se empleó el método de separación de fracciones proteicas en tampones de alta fuerza iónica descrito por Toldra et al (13), a materia prima y productos derivados conservadas en congelación a -18ํㅡ.
Electroforésis en geles de poliacrilamida con sodio dodecil sulfato (SDS-PAGE). La proteína miofibrilar extraída se adecuó siguiendo el protocolo modificado de Laemmli (14), cada muestra de proteína miofibrilar se diluyó en relación 1:4 con buffer de muestra y se prepararon geles a una concentración de 4\% para el gel de concentración y $12 \%$ para el de resolución. Para el montaje se empleó un equipo de electroforesis Mini Protean 3 cell de BioRad ${ }^{\circledR}$.

\section{RESULTADOS}

Los resultados de la medición de humedad, CRA y contenido proteico de materia prima y productos derivados se observan en la tabla 1.

El uso de proteínas como ingrediente en alimentos, está basado principalmente en la contribución a la textura, aceptabilidad y estabilidad física de los productos formulados (15). Los resultados obtenidos del TPA se muestran en la tabla 2.

Por condiciones de anisotropía del músculo y variabilidad en los datos; finalmente no se realizó TPA a la carne de Cajaro.

Tabla 1. Características evaluadas de materia prima, Surimi y productos derivados.

\begin{tabular}{lccc}
\hline Productos & $\begin{array}{c}\text { Humedad (g de agua/ } \\
100 \mathrm{~g} \text { de Producto) }\end{array}$ & $\begin{array}{c}\text { CRA (g de agua } \\
\text { /100 g de Producto) }\end{array}$ & $\begin{array}{c}\text { Proteína (g de proteína/ } \\
100 \mathrm{~g} \text { de producto) }\end{array}$ \\
\hline Cajaro & $81.8 \pm 3.42$ & $67.26 \pm 4.59$ & $14.74 \pm 0.99$ \\
Surimi & $77.42 \pm 4.72$ & $52.74 \pm 3.98$ & $15.83 \pm 1.40$ \\
Kamaboko & $72.05 \pm 3.74$ & $55.44 \pm 4.06$ & $18.66 \pm 1.35$ \\
Chikuwa & $74.71 \pm 6.47$ & $53.80 \pm 0.85$ & $18.40 \pm 1.45$ \\
\hline
\end{tabular}

Tabla 2. Análisis de perfil de textura (TPA) de materia prima, Surimi y productos derivados.

\begin{tabular}{lcccc}
\hline \multirow{2}{*}{ Producto } & \multicolumn{4}{c}{ Análisis TPA } \\
\cline { 2 - 5 } & Dureza (N) & Elasticidad $(\mathrm{mm})$ & Cohesividad & Adhesividad (NS) \\
\hline Cajaro & $* *$ & $* *$ & $* *$ & $* *$ \\
Surimi & $5.29 \pm 0.98$ & $16.26 \pm 0.26$ & $0.65 \pm 0.12$ & $-2.17 \pm 0.70$ \\
Kamaboko & $46.36 \pm 7.70$ & $16.88 \pm 0.19$ & $0.63 \pm 0.20$ & $* *$ \\
Chikuwa & $6.48 \pm 0.89$ & $16.42 \pm 0.30$ & $0.58 \pm 0.50$ & $* *$ \\
\hline
\end{tabular}




\section{DISCUSIÓN}

El contenido de humedad y proteína total en los filetes evaluados de Cajaro (Tabla 1) concuerda con los valores reportados por Yanar et al (10) para la misma especie. En la pasta de surimi, el contenido de humedad no presentó diferencias significativas $(p<0.05)$ con respecto a los filetes de Cajaro; así el contenido de humedad de la pasta obtenida $77.42 \pm 4.72 \%$ evidencio que las características del filete de Cajaro generan una pasta base de surimi dentro del estándar sugerido para esta propiedad que es de $78 \%$ (16). El descenso evidenciado en la concentración de proteínas totales en el surimi sugiere la lixiviación de una proporción de proteínas sarcoplásmicas que en el músculo de pescado se ha reportado entre $20 \%$ y el $30 \%$ de las proteínas totales (17). Para los productos derivados Kamaboko y Chikuwa, el aumento en el contenido de proteína relacionado con la disminución del contenido de humedad, refleja la concentración de proteínas miofibrilares con respecto a las propiedades de la materia prima y la pasta base, lo que también ha sido reportado para especies como el Jurel en este tipo de productos (18).

\section{Relación de la CRA con las características} texturales. La calidad demandada por consumidores tradicionales de surimi y productos derivados se ve afectada por la CRA. Es evidente el alto contenido de agua de los filetes de pescado en relación con una alta CRA dada la integridad del músculo (Tabla 1). En el proceso de obtención de surimi la ruptura de los miotomas se genera por el trabajo mecánico en el sistema de troceado y la adición de soluciones de alta fuerza iónica. En los productos Kamaboko y Chikuwa se evidencio un aumento en la CRA $55.44 \pm 4.06$ y $53.80 \pm 0.85 \mathrm{~g}$ de agua/ $100 \mathrm{~g}$ de producto, con respecto a la pasta base $52.74 \pm 3.98$, lo que se atribuye al polifosfato como estabilizador de $\mathrm{pH}$ y a la sacarosa como agente crioprotector en la pasta base de surimi, que sometida a temperaturas superiores a $60^{\circ} \mathrm{C}$, genera un ordenamiento de la estructura reticular de la proteína miofibrilar (19). Se han reportado valores de CRA de $54 \%$ en surimi obtenido de la especie marina Merlangius merlangus (20).
Los resultados del perfil de textura (Tabla 2) muestran un comportamiento adhesivo en el surimi, lo cual puede ser explicado por la ruptura del músculo acompañada de la lixiviación de las proteínas sarcoplásmicas que causan desestructuración, con una respuesta de mayor trabajo necesario para superar las fuerzas de atracción entre las miofibrillas que generan este comportamiento evidenciado en figura 2.

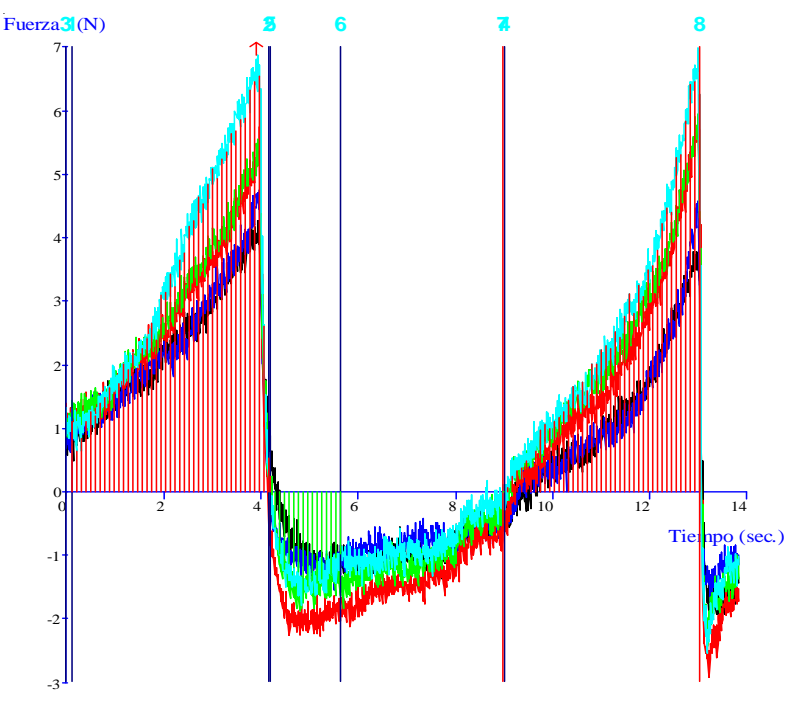

Figura 2. Análisis de Perfil de Textura en Surimi

Los productos elaborados (Figuras 3 y 4 ) muestran, a diferencia de la pasta base (Figura 5), un comportamiento cohesivo (Figuras 6 y 7) que se debe a los enlaces internos del gel formado. Las proteínas son desnaturalizadas por calor generando el desdoblamiento de la estructura terciaria y a la interacción de forma ordenada entre sí de diferentes tipos de enlaces como son los

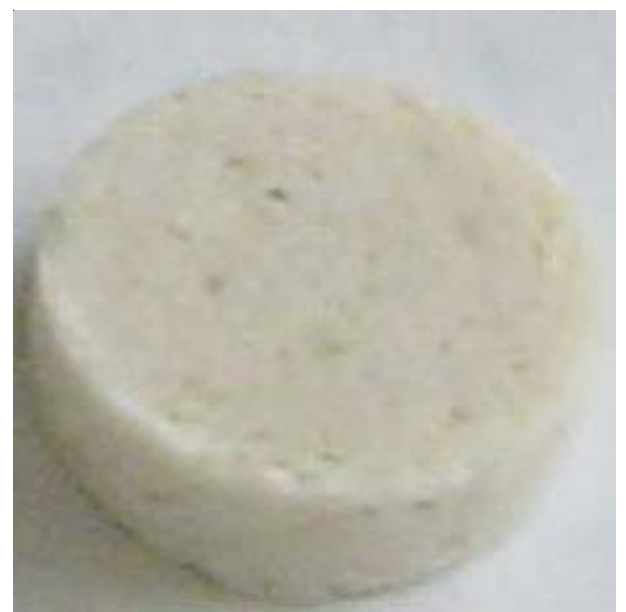

Figura 3. Producto derivado Kamaboko 


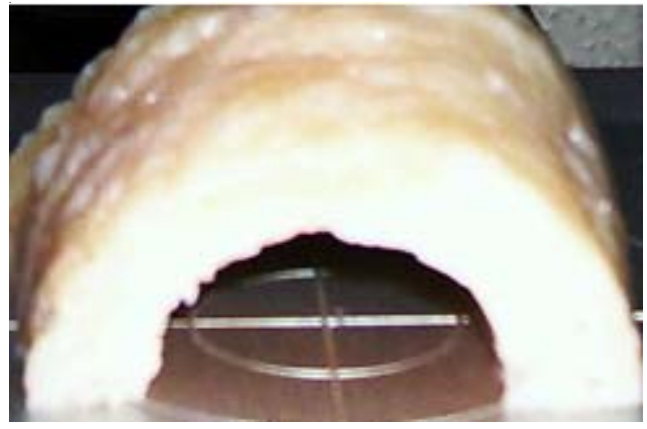

Figura 4. Producto derivado Chikuwa

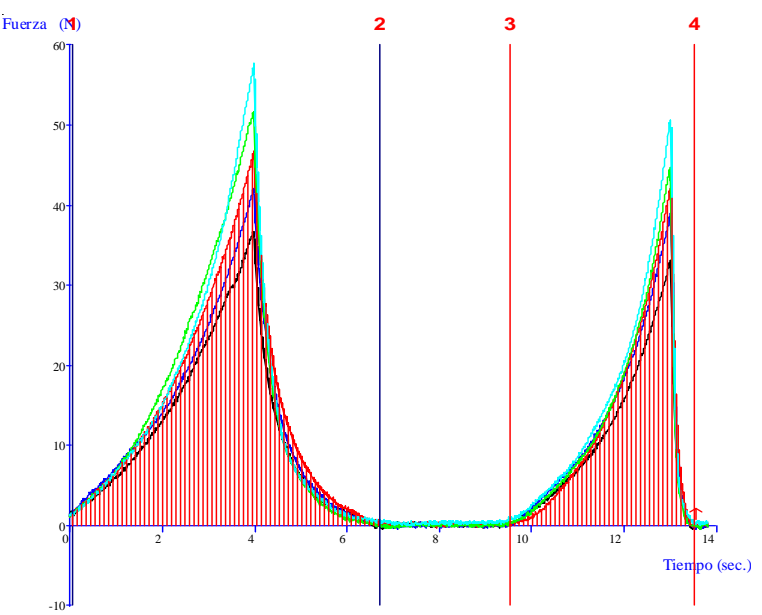

Figura 6. Análisis de Perfil de Textura en Kamaboko

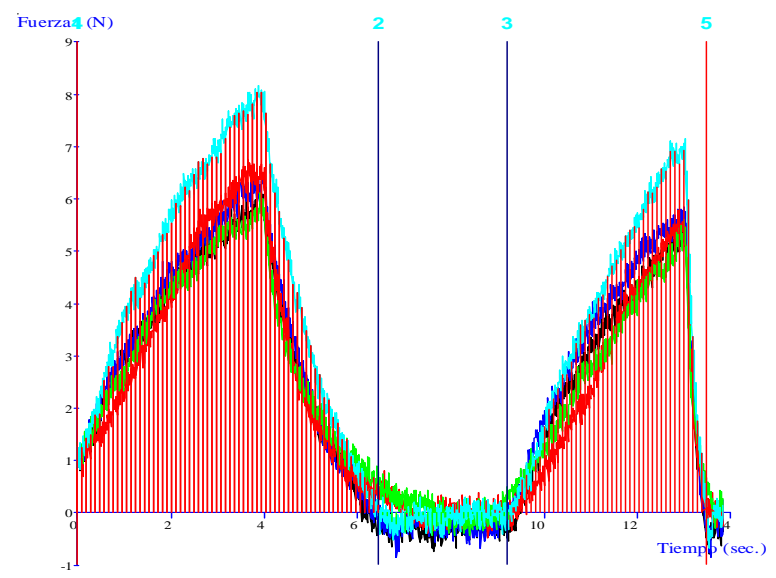

Figura 7. Análisis de Perfil de Textura en Chikuwa

puentes de hidrógeno, enlaces iónicos, puentes disulfuro y las asociaciones hidrófobas (16) que en su punto crítico, producen un gel compacto con infinito número de enlaces cruzados interpeptídicos formando una red tridimensional continua que retiene gran cantidad de agua (21).

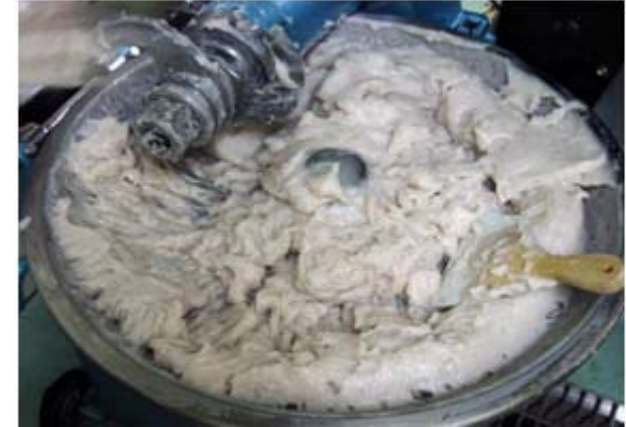

Figura 5. Pasta base (Surimi)

Los valores obtenidos evidencian que la elasticidad tiene una relación lineal con la CRA, típico de este tipo de productos. Para el Chikuwa la elasticidad se afecta por el encostramiento superficial, sin embargo, el alto contenido de agua y la forma del producto amortiguan este valor (22). En cuanto a las características texturales de gelificación se observó que el Chikuwa es más firme y quebradizo que el kamaboko, como se muestra en la figura 8, comportamiento igual al reportado para especies marinas como el Alaska Pollack con valores de 0.50 - 0.49 (19). Esto muestra que la funcionalidad del gel a partir de carne de Cajaro, se ve reflejada en la texturales.

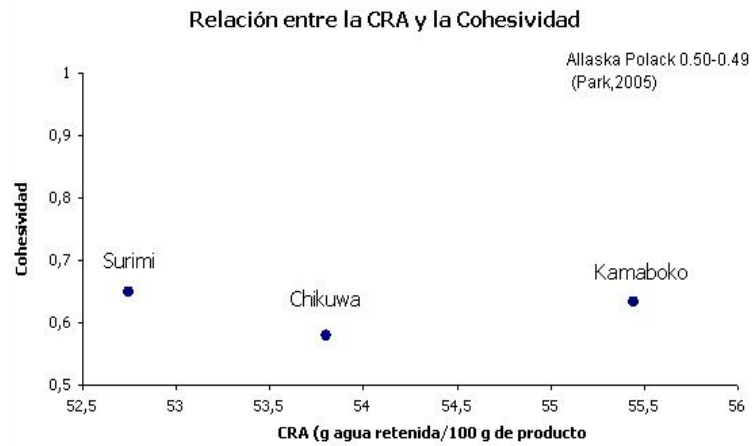

Figura 8. Relación entre CRA y cohesividad

Visualización de proteínas por electroforésis SDS-PAGE. En los electroforegramas se observa la separación de proteínas miofibrilares, y la identificación de la miosina como la proteína de mayor peso (200kDa aproximadamente), además de los cambios que esta presenta en los diferentes tratamientos. Pequeños cambios en las densidades de las bandas correspondientes a la miosina, disminuyeron gradualmente al realizar tratamiento térmico en los productos derivados (Figura 9). Este ordenamiento de las proteínas debidas al proceso es conocido 


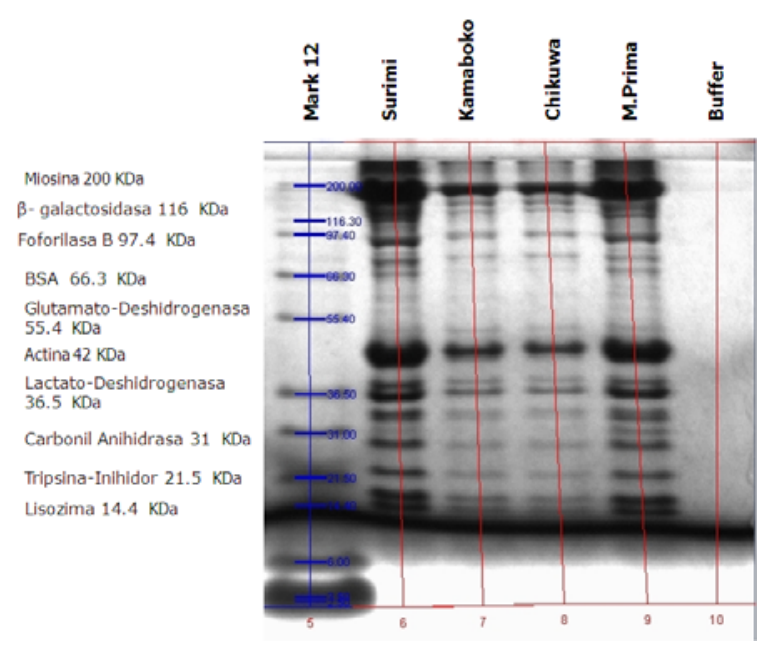

Figura 9. Electroforegrama de muestras frescas

como polimerización o "setting", y es el aspecto más importante en la calidad de este tipo de productos, donde se da una agregación proteica que genera un gel con un infinito número de enlaces cruzados interpeptídicos, formando una red tridimensional continua que retiene gran cantidad de agua; por lo que la miosina se encuentra organizada o aglomerada presentándose de forma compacta en el electroforegrama. La disminución en la concentración de las proteínas de bajo peso molecular, puede ser debido al tratamiento térmico, donde la cantidad de proteína soluble disminuye, lo que se puede atribuir a que estas proteínas se encuentran fuertemente ligadas generando estabilidad al producto (6).

En la figura 10 se evidencia pérdida de la miosina que puede ser desnaturalizada en la materia prima y en la pasta, por lo que solo se visualizan proteínas de bajo peso

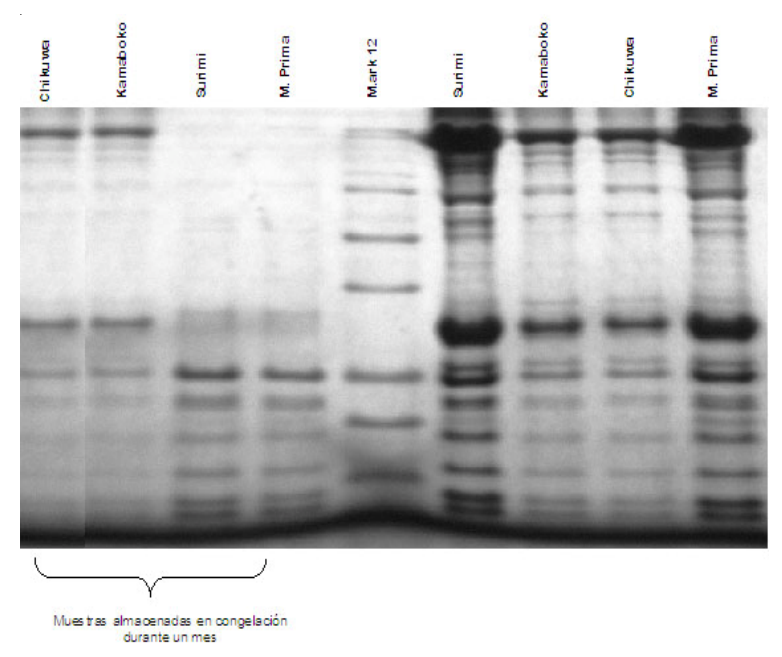

Figura 10. Electroforegrama de muestras frescas

molecular. En las muestras sometidas a tratamiento térmico la proteína permanece, aunque con menor intensidad.

Estos cambios se ven reflejados en la apariencia de la materia prima y la pasta, que por estar en congelación pierden la capacidad de retención de agua, contrario a lo ocurrido en el producto gelificado, sometido a tratamiento térmico que mantiene sus características.

En conclusión, se identificó el potencial que tiene el bagre Cajaro de la amazonía colombiana como especie para la producción de surimi y productos derivados. La calidad y cantidad de proteínas miofibrilares con características funcionales evidenciadas por las propiedades de capacidad de retención de agua, cohesividad y elasticidad, al igual que la estabilidad de la proteína en condiciones de congelación, lo que permitiría la obtención de productos tipo exportación.

\section{REFERENCIAS}

1. Ministerio de Agricultura y Desarrollo Rural. Diagnostico de la cadena productiva pesquera en la República de Colombia. [fecha de acceso febrero de 2008].URL disponible en: www.unido.org/fileadmin/import/ 24117_DiagnsticoNacionaldeColombia.pdf
2. Food and Agriculture Organization (FAO). Fisheries and Aquaculture Department. Trends in consumption. [fecha de acceso febrero de 2008] URL disponible en: http://www.fao.org/ fishery/topic/3463. 
3. Suzuki T. Fish and krill protein: processing technology. London: Applied Science Publishers Ltd; 1981.

4. George M. Hall, Ahmad NH. Tecnología del procesado del pescado. España: Acribia; 2001. ISBN 84-200-0938-5

5. Fish information and services. Reporte de mercado y exportaciones de surimi y productos derivados. USDA-FAS. [fecha de acceso febrero de 2008] URL disponible en: http://www. fis.com/fis/ reports/report. asp?l=e\&specie $=32$.

6. Ibarra L. Efectos sobre la calidad y funcionalidad del músculo de manto de calamar gigante (Dosidicus gigas) sometido al almacenamiento en hielo. México: Instituto tecnológico de TEPIC; 2006.

7. Flores J, Bermell S. Propiedades Funcionales de las Proteínas Miofibrilares: Capacidad de Retención de Agua. Agroquímica y Tecnología de Alimentos. 1984; 24: 151-158.

8. Badui D, Bourges-Rodriguez $\mathrm{H}$, Anzaldua-Morales A. Química de los Alimentos. México: Longman de México Editores; 1999.

9. Huff-Lonergan E, Lonergan SM. Mechanisms of Water-Holding Capacity of Meat: The Role of Postmortem Biochemical and Structural Changes. J Food Sci 2005; 194-204.

10. Jica, YIC Center, Departament of fishing and fish processing technology. Handling and primary processing of fishery products Course. Yokohama; 2003.

11. AOAC Oficial Method of analysis. 14th edition. Washington. D.C.: Association of Official Analytical Chemist; 1990.

12. Foegeding EA, Ramsey SR. Rheological and water holding properties of gelled meat batters containing iotacarrageenan, kappa-carrageenan or xanthan gum. J Food Sci 1987; 52(3): 549-553.
13. Toldra F, Miralles M, Flores J. Protein extractability in dry-cured ham. Food Chem 1992; 391-394.

14. Ausubel F. Analysis of Proteins. In: Current Protocols in Molecular Biology Vol 2. USA: John Wiley and Sons, Inc. 2005.

15. Murphy D, Gilroyb JF, Kerrya DJ, Buckleya JP. Evaluation of surimi, fat and water content in a low/no added pork sausage formulation using response surface methodology. J Meat Sci 2004; 66: 689-701.

16. Lanier TC, Hart K, Martin RE. A Manual of Standard Methods for Measuring and Specifying the Properties of Surimi. Raleigh (USA): U. North Carolina Sea Grant College Program; 1991.

17. Japan International Cooperation Agency (JICA) Science of processing marine food products. Kanagawa International Fisheries training centre. 1992.

18. Lluch MA, Álvarez E, Puig A. Preparaciôn y caracterización química y microestructural de surimi de merluza (Merluccius merluccius) y de jurel (Trachurus trachurus). Food Sci Technol Int 1997; (3): 49-60.

19. Park J. Surimi and Surimi Seafood 2 Ed. Tay; 2005.

20. Chung KH, Lee CM. Relationships between physicochemical properties of nonfish protein and textural properties of protein incorporated surimi gel. J Food Sci 1990; 55: 972-975.

21. Nakai S, Modler W. Food Proteins Processing Aplications. $1^{\text {a }}$ ed. New York: Wiley-VCH; 2000.

22. Webb EL. Process control parameters for Skipjack tuna (Katsuwonas pelamis) precooking [tesis doctoral]. Raleigh: North Carolina State Univ.; 2003. 